The Journal of

Thoracic and

Cardiovascular

Surgery

\title{
Surgical intervention for T4 lung cancer with infiltration of the thoracic aorta: Are we back to the archetype of surgical thinking?
}

Walter Klepetko, MD

See related article on page 804 .

From the Medical University of Vienna, Department of Cardiothoracic Surgery, Vienna, Austria.

Received for publication Aug 24, 2004; accepted for publication Aug 27, 2004.

Address for reprints: Walter Klepetko, MD, Professor of Special Thoracic Surgery, Medical University of Vienna, Department of Cardiothoracic Surgery, Waehringer Guertel 18-20, A-1090 Vienna, Austria (Email: walter.klepetko@meduniwien.ac.at).

J Thorac Cardiovasc Surg 2005;129:727-9

$0022-5223 / \$ 30.00$

Copyright $\odot 2005$ by The American Association for Thoracic Surgery

doi:10.1016/j.jtcvs.2004.08.046

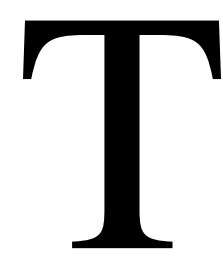

he philosophy that radical surgical resection of all malignant tissue can be curative, even for advanced tumors, has widely influenced the therapeutic thinking of surgeons in the early days and, to some degree, still remains alive in many surgeons at present. In view of our modern understanding of tumor biology in general and the grim prognosis of bronchial cancer in particular, the value of such extended operations must, however, seriously be questioned. In this issue of the Journal, the article "Surgical resection for lung cancer with infiltration of the thoracic aorta" by Ohta and colleagues ${ }^{1}$ again raises the question of whether surgical intervention for advanced tumors, particularly for T4 tumors with infiltration of the large vessels, can inhere oncologic benefit for our patients or rather must be seen as an extreme operation, which is more of technical attractiveness to the surgeon than of therapeutic value for the patient.

The question can be approached from different sides. Above all, one has to ask for the statistical proof of the survival advantage for patients treated for locally advanced T3/T4 bronchial cancer. One must accept that this advantage can hardly be demonstrated from the existing literature. All documented experience about surgical intervention for T3/T4 non-small cell lung cancer has been collected in rather small series only, ${ }^{2-4}$ which is in clear contrast to the large number of patients that usually is necessary to demonstrate treatment benefit of only moderate extent. For example, in a recently published prospective randomized study by the International Adjuvant Lung Cancer Trial Collaborative Group, ${ }^{5}$ more then 1800 patients were necessary to document a $4.1 \%$ survival benefit after 5 years in a group of patients who received adjuvant chemotherapy for non-small cell lung cancer stages I, II, and III. Furthermore, results of treatment of T3/T4 tumors usually are obtained over considerably long periods of time, and there is uniform lack of a well-matched control group that would allow serious statistical comparison. Therefore, our inability to provide clear statistical evidence for treatment of such rather rare tumor situations must not be regarded as indicative that the proposed therapy necessarily lacks benefit at all. Localized tumors with infiltration of the thoracic aorta represent an even more rare entity than the already small category of other advanced tumors with infiltration of the vertebral column, ${ }^{6}$ the carina, ${ }^{7}$ or the apex of the chest. ${ }^{8}$ At least for the latter 2 situations, accepted criteria for surgical treatment do exist, and survival benefit from combined treatment modalities, including surgical intervention, is anticipated, even without existing statistical evidence. The problem is, however, not infrequent in modern medicine, where the challenge to deal with more and more difficult and complex situations clearly implies that we are increasingly 
confronted with conditions that simply will never occur at a sufficiently high rate to allow meaningful statistical analysis.

But do we really lack all statistical feedback for the selection of patients with advanced tumors for surgical intervention? Certainly not, because it has repeatedly been demonstrated in the surgical literature that the prognosis after operations for T3/T4 tumors mainly depends on the $\mathrm{N}$ stage. ${ }^{9}$ Whether one looks at results after combined resection of the lung and the chest wall ${ }^{10}$ or after resection of the lung and the central airways, ${ }^{7}$ it uniformly turns out that patients with N0 or minimal N1 disease do significantly better after radical resection, a finding that clearly justifies operative therapy in these patients. In view of these observations, one would be tempted to apply similar criteria for operation of patients with localized tumors infiltrating the aorta. In fact, this is precisely the message that comes out of Dr Ohta's article, ${ }^{1}$ in which patients with N0 disease had an impressively high $70 \%$ five-year survival after radical surgical intervention.

On the basis of these considerations, should we therefore be allowed to routinely recommend such an aggressive surgical treatment as combined resection of the lung and the aorta represents for our patients? The answer clearly is no.

In addition to the oncologic aspects, operative treatment of tumors with infiltration of the thoracic aorta differs from treatment of other advanced tumors in the important aspect of the need for cardiopulmonary bypass for resection.

This implies not only a clear increase in surgical complexity but also implies increased perioperative risks as well. In fact, the mortality and morbidity that is reported for the operation is considerable, ${ }^{11,12}$ which again is demonstrated in the current article by Ohta and colleagues, ${ }^{1}$ in which results in this regard are not substantially better than those reported in previous articles. Another reason for the high morbidity and mortality of the operation is the limited experience that can be built up with a procedure that is performed on such a rare basis. Both the technical complexity of the operation and its rare occurrence therefore suggest centralization of the procedure to departments that express profound and continuous interest in such problems and that at the same time have a high degree of experience with both cardiac and general thoracic surgical procedures.

Another important drawback of the use of cardiopulmonary bypass is potential scattering of tumor cells by suction of blood that is then returned to the circuit system. ${ }^{12}$ As a consequence, this can be expected to result in generalization of a thus far localized disease; to achieve prognostic improvements, the long-term outcome would be even more dismal. Two technical variants exist to avoid such a spread of tumor cells. One, which has also been applied in a few patients of Dr Ohta's series, represents the use of a passive shunt. The other, a more sophisticated approach, is the use of a femoro-femoral heparinized extracorporeal membrane oxygenation system for resection of the descending aorta, which avoids the need for full anticoagulation of the patient during the resection and therefore the need for return of suctioned blood into the circuit. ${ }^{12}$

After the perception that only patients with N0 or minimal N1 disease will potentially have a benefit from the complex resection, the issue of adequate staging becomes important. This must be seen as an absolute prerequisite that implies the use of invasive staging procedures, and any detected N2 disease should automatically exclude the patient from surgical treatment. However, we must be aware that the quality of our staging frequently is limited in cases in which direct video endoscopic access to subcarinal lymph nodes might be prohibited by the adjacent tumor itself.

What has to be discussed further is the role of neoadjuvant chemotherapy in this particular setting. The feasibility of neoadjuvant chemotherapy in the treatment of different forms of T3 and T4 tumors has repeatedly been demonstrated, ${ }^{13}$ and it is highly valid for T4 tumors with infiltration of the great vessels as well. However, of the 3 general goals of neoadjuvant chemotherapy, which are downsizing of large tumors, eradication of undetected micrometastasis, and downstaging of preoperatively detected lymph node involvement, only the first 2 are applicable for treatment of T4 tumors with aortic infiltration because any preoperatively detected N2 disease should automatically exclude these patients from further operations.

If we summarize these considerations, surgical resection of T4 tumors with infiltration of the aorta can be offered under very strict conditions. It should only be considered if, the tumor is localized, after exclusion of N2 involvement and after neoadjuvant chemotherapy. Excellent functional status of selected patients is mandatory, and the operation should be performed in a specialized institution.

The operative morbidity and mortality of the procedure remains to be seen as the major concern and carefully has to be balanced against the scarcely existing evidence of oncologic benefit for the patient. However, potential prognostic benefit for combined resection of the lung and the aorta should not be denied categorically simply on the basis of the argument of limited statistical proof.

\section{References}

1. Ohta M, Hirabayashi H, Shiono H, Minami M, Maeda H, Takano H, et al. Surgical resection for lung cancer with infiltration of the thoracic aorta. J Thorac Cardiovasc Surg. 2005;129:804-8.

2. Klepetko W, Wisser W, Birsan T, Mares P, Taghavi Sh, Kupilik N, et al. T4 lung tumors with infiltration of the thoracic aorta: is an operation reasonable. Ann Thorac Surg. 1999;67:340-4.

3. Fukuse T, Wada H, Hitomi S. Extended operation for non-small cell lung cancer invading great vessels and left atrium. Eur J Cardiothorac Surg. 1997;11:664-9.

4. Pitz CM, De La Riviere AB, Van Swieten HA, Duurkens AM, Lammers JW, Van den Bosch JMM. Surgical treatment of pancoast tumours. Eur J Cardiothorac Surg. 2004;26:202-8. 
5. The International Adjuvant Lung Cancer Trial Collaborative Group. Cisplatin-based adjuvant chemotherapy in patients with completely resected non-small cell lung cancer. $N$ Engl J Med. 2004;350:351-60.

6. Grunenwald DH, Mazel Ch, Girard Ph, Veronesi G, Spaggiari L, Gossot D, et al. Radical en bloc resection for lung cancer invading the spine. J Thorac Cardiovasc Surg. 2002;123:271-9.

7. Mitchell JD, Mathisen DJ, Wright CD, Wain JC, Donahue DM, Allan JS, et al. Resection for bronchogenic carcinoma involving the carina: long-term results and effect of nodal status on outcome. J Thorac Cardiovasc Surg. 2001;121:465-71.

8. Fadel E, Missenard G, Chapelier A, Mussot S, Leroy-Ladurie F, Cerrina $\mathrm{J}$, et al. En bloc resection of non-small cell lung cancer invading the thoracic inlet and intervertebral foramina. $J$ Thorac Cardiovasc Surg. 2002;123:676-85.

9. Grunenwald DH, Andre F, Le Pechoux C, Girard Ph, Lamer Ch, Laplanche A, et al. Benefit of surgery after chemoradiotherapy in stage IIIB (T4 and/or N3) non-small cell lung cancer. $J$ Thorac Cardiovasc
Surg. 2001;122:796-802.

10. Burkhart HM, Allen MS, Nichols FC, Deschamps C, Miller DL, Trastek VF, et al. Results of en bloc resection for bronchogenic carcinoma with chest wall invasion. J Thorac Cardiovasc Surg. 2002; 123:670-5.

11. Tsuchiya R, Asamura H, Kondo H, Goya T, Naruke T. Extended resection of the left atrium, great vessels, or both for lung cancer. Ann Thorac Surg. 1994;57:960-5.

12. Baron O, Jouan J, Sagan C, Despins P, Michaud JL, Duveau D. Resection of bronchopulmonary cancers invading the left atriumBenefit of cardiopulmonary bypass. Thorac Cardiovasc Surg. 2003; 51:159-61.

13. Rusch VW, Giroux DJ, Kraut MJ, Crowley J, Hazuka M, Johnson D, et al. Induction chemoradiation and surgical resection for non-small cell lung carcinomas of the superior sulcus: initial results of southwest oncology group trial 9416 (intergroup trial 0160). J Thorac Cardiovasc Surg. 2001;121:472-83. 